\title{
SILENT OSTEOPOROSIS IN ASSOCIATION WITH OTHER ORTHOPEDIC DISEASES
}

\author{
Thamer A Hamdan*, Mubder A Mohammed Saeed ${ }^{\#}$ \& Saad J Abdulsalam ${ }^{@}$ \\ *FRCS, FRCP, FACS, FICS, Professor Of Orthopedic Surgery, Chancellor of Basrah University. \\ ${ }^{\#}$ FICMS, Assistant Professor Of Orthopaedic Surgery, Basrah General Hospital, ${ }^{@}$ FACMS, Orthopedic \\ Surgeon, Al-Karkh General Hospital, Baghdad.
}

\begin{abstract}
Osteoporosis is the most common metabolic bone disease. It is a major global health problem that increases dramatically as people getting older than before because of good health services.

The aim of the study is to assess how far osteoporosis is associated with orthopedic diseases and to increase the awareness in the mind of orthopedic surgeons for osteoporosis in patients who are not suspected apparently to have this disease.

A sample of 522 patients referred to Dual-energy X-ray absorptiometry (DXA) clinic by orthopedic surgeons or rheumatologists was taken during a seven months period, in two centers, Basrah, 259 patients and Mosul, 263 patients. All the patients had back pain, joint pain, bone pain, fracture or other musculoskeletal complains. The only method used to assess osteoporosis in our patients was the DXA scan.

Of the total 522 patients, the results of DXA scan was normal in 136 patients (26\%), osteopenia in 178 patients (34\%), and osteoporosis in 208 patients (40\%). Back pain was the main cause of referral 184 (35\%), followed by joint pain 138 (26.5\%), bone pain 74 (14\%), fracture 28 (5.5\%), and others 98 (19\%).

In conclusion, osteoporosis may be a silent disease, even in patients with complains like joint pain, bone pain, or radicular symptoms.
\end{abstract}

\section{Introduction}

Steoporosis is a systemic skeletal disease characterized by low bone mass and structural deterioration of bone tissue leading to bone fragility and increased risk of fracture ${ }^{1-2}$.

The global burden of osteoporotic fractures is significant, particularly in the developed countries, with estimated fractures $1.75 \%$ of the burden of noncommunicable diseases in Europe and $0.83 \%$ worldwide. Nine million osteoporotic fractures were estimated to have occurred worldwide in the year 2000, with 1.6 million hip and 1.4 million vertebral fractures, the greatest number of these occurring in Europe (34.8\%). A total of 2.7 million osteoporotic fractures were estimated in men and women in Europe with approximately direct cost of $€ 36$ billion $^{1}$. The fracture incidence is increased in some countries with age and population number, and expected to rise more. Hip fractures will reach to 6.3 million worldwide in $2050^{1}$.

Risk factors for osteoporosis are; Genetic, endocrine, malabsorption, neurologic, and rheumatologic diseases. Certain drugs have also been linked to decreased bone mineral density(BMD) so increased fracture risk. Lifestyle factors may influence both the development of strong bone before peak bone mass is reached (about 20-29 years of age) and the loss of bone after that. A comprehensive risk assessment for the development of osteoporosis and the risk of fracture would include; evaluation of risk factors such as lifestyle, diseases, and drug factors, as well as BMD testing when indicated. The National Osteoporosis Foundation (NOF) 2014 Clinician's Guide to Prevention and Treatment of Osteoporosis recommends the evaluation of osteoporosis risk in all postmenopausal 
women and all men aged 50 years or older. Dual-energy x-ray absorptiometry is a key indicator of fracture risk, and the NOF recommends screening of patients at risk of low BMD and fracture.

The NOF also recommends the use of vertebral imaging to complement BMD testing in certain individuals to further evaluate future fracture risk and possibly direct patient education ${ }^{3-4}$.

Fracture Risk Assessment Tool (FRAX) is developed to further assess women with postmenopausal fragility fractures ${ }^{5}$.

Certain co-morbidities such as smoking, use of glucocorticoids, presence of rheumatoid arthritis, alcohol use are additional risk factors ${ }^{6}$.

Investigation of the newly diagnosed osteoporotic person should include a screen for malignancy and metabolic bone biochemical abnormalities. Biochemical markers of bone turnover are available but their precise clinical role has not been established ${ }^{7}$.

The primary goal of the treatment of osteoporosis is prevention of fragility fractures and the potential devastating complications resulting in increased morbidity and mortality and decreased function ${ }^{8-10}$.

\section{Patients and methods}

This study was conducted in two centers; the first is Al-Zahraa DXA clinic in Basrah, south of Iraq, the second is DXA clinic in Ibn-Sina hospital in Mosul, north of Iraq. A sample of patients referred by orthopedic surgeons or rheumatologists to do DXA scan was taken as a part of investigations. The DXA machine in Basrah, was (Lunar General Electric, version 11, PRODIGY). In Mosul, the machine was (Holligic Discovery). The total sample size was 522 patients, 74 males and 448 females, with age range from 18 to 83 years. All of them having back pain, joint pain, bone pain (nonspecific bone pain and generalize body aches), fragility fractures, and others such as neurological symptoms like lumbar or cervical radicular pain.

All patients were evaluated by detailed history according to special questionnaire prepared for this purpose. DXA scan was done for all patients.

Patients were assigned according to their age group, cause of referral to the DXA clinic, their body weight, social habits (which contribute to the development of the disease, like physical activity, exposure to sun light, dietary calcium intake, smoking ...etc.). The patients were asked about their past medical and surgical history relevant to the disease; DM, endocrine, rheumatologic, or ischemic heart diseases. History of fragility fracture for patient or first degree relative, certain operations like hysterectomy, oophrectomy and orchidectomy and drug history, particularly steroids, antacids, anticoagulants (heparin) and anti-epileptic drugs.

In the light of WHO classification, the patients were put into three groups according to T-score recording; normal (-1SD) and above, osteopenia (between $-1 \&-2.5 S D)$, and osteoporosis (-2.5SD) \& below.

\section{Results}

The total sample size was 522 patients, 259 in Basrah and 263 in Mosul. The results of DXA scan of the patients was; normal 136 patient (26\%) , osteopenia 178 patients (34\%), and osteoporosis 208 patients, (40\%) of the sample as demonstrated in Table I.

Table I: DXA results of the patients

\begin{tabular}{|l|c|c|c|c|}
\hline & Normal & Osteopenia & Osteoporosis & Total \\
\hline Basrah & 37 & 94 & 128 & 259 \\
\hline Mosul & 99 & 84 & 80 & 263 \\
\hline Total & 136 & 178 & 208 & 522 \\
\hline
\end{tabular}


In this study, the 522 patients were 74 two centers as shown in Table II. males and 448 females, distributed in the

Table II: Gender distribution in the sample

\begin{tabular}{|l|c|c|c|}
\hline Gender & Male & Female & Total \\
\hline Basrah & 41 & 218 & 259 \\
\hline Mosul & 33 & 230 & 263 \\
\hline Total & 74 & 448 & 522 \\
\hline
\end{tabular}

The age distribution of the patients was from 18 to $83 \mathrm{yr}$. The patients were assigned into four groups; less than $30 \mathrm{yr}$.
(16 patients), 31-45 yr. (58 patients), 4660yr. (238 patients) and over 60 yr. (210 patients) as shown in Table III.

Table III: Age distribution of the patients

\begin{tabular}{|l|c|c|c|c|c|}
\hline Age (Yr.) & $\mathbf{3 0}$ or less & $\mathbf{3 1 - 4 5}$ & $\mathbf{4 6 - 6 0}$ & $\mathbf{6 0}$ or more & Total \\
\hline Basrah & 5 & 23 & 117 & 114 & 259 \\
\hline Mosul & 11 & 35 & 121 & 96 & 263 \\
\hline Total & 16 & 58 & 238 & 210 & 522 \\
\hline
\end{tabular}

According to the cause of referral, patients were separated into five groups; back pain, joint pain, bone pain (non-specific bone pain and generalize body aches), fractures and others (which include patients with neurological symptoms like lumbar or cervical radicular pain, or malignancy), as shown in Table IV.

Table IV: Distribution according to cause of referral to DXA scan

\begin{tabular}{|l|c|c|c|c|c|c|}
\hline & Back pain & Joint pain & Bone pain & Fracture & Other & Total \\
\hline Basrah & 120 & 46 & 47 & 10 & 36 & 259 \\
\hline Mosul & 64 & 92 & 27 & 18 & 62 & 263 \\
\hline Total & 184 & 138 & 74 & 28 & 98 & 522 \\
\hline
\end{tabular}

Back pain was the main cause of referral (35\%), followed by joint pain (26.5\%), bone pain $(14 \%)$, fracture $(5.5 \%)$, and others (19\%). For the patients with back pain, only 22(12\%) were normal, 71(38.5\%) had osteopenia, and half of them 91(49.5\%) were osteoporotic as shown in Table V.

Table V: Assessment of DXA results in patients with back pain

\begin{tabular}{|l|c|c|c|c|}
\hline & Normal & Osteopenia & Osteoporosis & Total \\
\hline Basrah & 10 & 42 & 68 & 120 \\
\hline Mosul & 12 & 29 & 23 & 64 \\
\hline Total & 22 & 71 & 91 & 184 \\
\hline
\end{tabular}

Patients with joint pain were 138, normal were 51 (37\%), osteopenic 53(38\%), and osteoporotic patients were 34 (25\%) as in Table VI.

Table VI: Assessment of DXA results in patients with joint pain

\begin{tabular}{|l|c|c|c|c|}
\hline & Normal & Osteopenia & Osteoporosis & Total \\
\hline Basrah & 19 & 15 & 12 & 46 \\
\hline Mosul & 32 & 38 & 22 & 92 \\
\hline Total & 51 & 53 & 34 & 138 \\
\hline
\end{tabular}


Patients with bone pain were 74 , of them, 22 (30\%) were normal, 24 (32\%) had osteopenia, and 28 (38\%) were osteoporotic as in Table VII.

Table VII: Assessment of DXA results in patients with bone pain

\begin{tabular}{|l|c|c|c|c|}
\hline & Normal & Osteopenia & Osteoporosis & Total \\
\hline Basrah & 12 & 15 & 20 & 47 \\
\hline Mosul & 10 & 9 & 8 & 27 \\
\hline Total & 22 & 24 & 28 & 74 \\
\hline
\end{tabular}

Total patients with fractures were 28 patient, only 2 (7\%) of them had osteopenia, the other 26 (93\%) were osteoporotic as in Table VIII.

Table VIII: Assessment of DXA results in patients with fracture

\begin{tabular}{|l|c|c|c|c|}
\hline & Normal & Osteopenia & Osteoporosis & Total \\
\hline Basrah & - & 2 & 8 & 10 \\
\hline Mosul & - & - & 18 & 18 \\
\hline Total & - & 2 & 26 & 28 \\
\hline
\end{tabular}

The last group, others (which include patients with neurological symptoms like lumbar or cervical radicular pain, or malignancy) were 98 patients, the DXA results were as follows; normal 41(42\%), osteopenia 28 (28.5\%), and osteoporosis 29(29.5\%) as in Table IX.

The results of comparing the two centers regarding the DXA scan are shown in table X.

Table IX: Assessment of DXA results in patients with other conditions

\begin{tabular}{|l|c|c|c|c|}
\hline & Normal & Osteopenia & Osteoporosis & Total \\
\hline Basrsh & 12 & 12 & 12 & 36 \\
\hline Mosul & 29 & 16 & 17 & 62 \\
\hline Total & 41 & 28 & 29 & 98 \\
\hline
\end{tabular}

Table X: Comparison between Basrah \& Mosul centers in DXA results

\begin{tabular}{|l|c|c|c|c|}
\hline & Normal & Osteopenia & Osteoporosis & Total \\
\hline Basrah & $37(14 \%)$ & $94(36 \%)$ & $128(50)$ & 259 \\
\hline Mosul & $99(38 \%)$ & $84(32 \%)$ & $80(30 \%)$ & 263 \\
\hline
\end{tabular}

\section{Discussion}

Osteoporosis is an inevitable part of ageing, but in spite of that it is preventable. In clinical practice, there are various determinants of bone quality which are not generally measurable and therefore cannot help the clinician to predict fracture risk. Therefore, the cornerstone of evaluation is the measurement of BMD, which correlates highly with fracture risk and allows the clinician to determine the need for drug therapy and can also help to monitor the response to therapy.

Because DXA has become the most commonly used method to measure BMD, which adopted by WHO, this study utilizes it as a tool to diagnose osteoporosis.

In this study, the sample size (522 patients) was studied during seven months period in two centers. The sample is relatively small, but in comparison with 
studies in the nearby countries, it is accepted. Haider Al Attia and Bruce Adams, in the UAE, in 2007, studied 805 patients, over nine months period ${ }^{11}$. Another study done in Beirut, Lebanon by R. Baddoura et al, the total sample was 307 patients during fall $2001^{12}$.

Male referral in our study was 74 (14\%), $34 \%$ of the males had osteopenia, 36\% osteoporosis, and $30 \%$ were normal, but in the study done in $\mathrm{UAE}$, by Haider $\mathrm{Al}$ Attia and Bruce Adams, they found that male referral was $8.8 \%$ of the total sample, about half of them (49\%) were osteopenia, (22.5\%) had osteoporosis, and $(28 \%)$ were normal ${ }^{11}$.

DXA results for the females was relatively comparable to that in Europe; In our study; Normal ladies were 114 (26\%), osteopenia 153 (34\%) and osteoporosis 181 (40\%). In a study done by Mikail A Boyanov, 2600 Bulgarian women aged 25-87 years referred for bone densitometry screening, he found that in women aged 50 and older the prevalence of osteoporosis reached $37.31 \%$ in the spine, and $16.14 \%$ in the left hip. Osteopenia was $39.74 \%$ in the spine and $65.57 \%$ in both hips ${ }^{13}$.

The use of a check list of risk factors for osteoporosis may increase the appropriate use of DXA in patients over the age of $50^{14}$. In this study, $72 \%$ of the patients had one or more risk factors to be sent for DXA scan. K. H. Rubin et al determine the relationship between risk factors and use of DXA scans. They found that $10.3 \%$ of the women are without risk factors and only $36 \%$ of the women with three or more risk factors ${ }^{15}$. According to the cause of referral, back pain was the most common cause of referral (35\%), followed by joint pain (26.5\%), others (19\%), bone pain (14\%), and fracture (5.5\%). Haider Al Attia and Bruce Adams found that the most common cause for DXA referral was corticosteroid therapy (20.5\%), bone rarefaction on radiographs $(13 \%)$ and fragility fractures $(12 \%)^{11}$.

In another study done in Basrah by $\mathrm{T}$. A. Hamdan and A. J. Aldawas, in 2011, they assess forty-six patients with spondylolisthesis and they found that $19.5 \%$ of the patients had osteopenia, and $15.2 \%$ of them were osteoporotic ${ }^{16}$.

Silent osteoporosis is a frequent problem after the age of sixty, but it may hide itself under the cover of common spinal pathology, like spinal stenosis, or spondylolisthesis ${ }^{17}$.

The results from the two centers in our study (Basrah and Mosul) were comparable.

\section{Conclusion}

The silent epidemic of osteoporosis has been a challenge. We are now in the beginning to appreciate the magnitude of this disorder in our population. All the medical staff, especially orthopedic surgeons and rheumatologists should be aware of this disease, as it is present in patients with unusual presentations like joint pain, backache or neurological symptoms.

Estimation of the risk factors and awareness for the guidelines and indications of BMD testing is vital in predicting the presence of osteoporosis. Male patients are also at risk for developing this disease 


\section{References}

1. Richard A. Watts, Philip G. Conaghan, Christopher Denton, Helen Foster, John Isaacs, and Ulf Müller-Ladner, Oxford Textbook of Rheumatology. Fourth Edition, Oxford University Press 2013, P 1225-1236.

2. Yoichi Shimada, Naohisa Miyakoshi; Osteoporosis in Orthopaedics, Assessment and Theraputic Options. First edition, Springer Japan 2016, P135-.155

3. Michelle L. Rager and Dawn E. Havrda, ACSAP 2016 Book 1, Endocrinologic, Rheumatologic Care, P 65-66.

4. David M Reid; Handbook of Osteoporosis, Springer, 2011. P 49-59.

5. Karen Law \& Aliza Lipson; Rheumatology board review; Wiley-Blackwell, 2014, P 150.

6. James Yue Richard, Guyer J. Patrick, Johnson Larry Khoo, Stephen Hochschuler, The comprehensive treatment of the aging spine : minimally invasive and advanced techniques. First edition, Saunders, P 70-71.

7. Philip Seo, Alan Hakim, Gavin Clunie, and Inam Haq, Oxford American handbook of rheumatology, 2nd edition. Oxford University Press 2013, P 449-450.

8. Lisa K. Cannada; Orthopedic Knowledge Update 11, published by the American Academy of Orthopedic Surgeons 2014, P 195-197.

9. Rene Rizzoli; Atlas of Postmenopausal Osteoporosis,3rd ed. Springer 2010, P 83-86.

10. William M. Ricci \& Robert F. Ostrum, Orthopaedic Knowledge Update: Trauma 5, copyright 2016, American Academy of Orthopaedic Surgeons, P 637-638.

11. Haider Al Attia and Bruce Adams; 'Osteoporosis in men : are we referring enough for DXA and how? . Clinical Rheumatology, 2007, 26: 1123-1126.

12. R. Baddoura, J. Okais, H. Awada, M. Salamoun, G. Ayoub . N. Ziadé, G. El Hajj-Fuleihan: An audit of bone densitometry practice with reference to ISCD, IOF and NOF guidelines". Osteoporosis International, 2006, 17: $1111-1115$.

13. Mikail A. Boyanov ;"Prevalence of low central bone mineral density in a Bulgarian female referral population : a pilot study . Rheumatology international (2006) 26:523-529.

14. Richards J. Steuart, Amdur Richard L. and kerr Gail S. ; "Osteoporosis risk factor assessment increases the appropriate use of DXA in men and reduce ethnic disparity". Journal of clinical rheumatology : February 2008, volume 14, Issue $1, \mathrm{p}$ 1-5.

15. K.M. Rubin, bo Abrahamsen, Pernille Hermann, Kim Brixen "Prevalence of risk factors for fractures and use of DXA scanning in Danish women . A regional population - based study", Osteoporosis International(2011) 22:1401-1409.

16. Thamer A. Hamdan and Ahmad J. Aldawas ; Varieties of Treatment for Lumbar Spondylolisthesis Prospective Clinical Study of Fourty-six Patients . Council of Iraqi Board for Medical Specilization , 2011.

17. Thamer A. Hamdan."Remember there are hidden flames in surgical practice ". Basrah Journal of Surgery ; volume 17 No.1 march 2011; (P 1-2) 